\title{
O Jogo com Regras Explícitas Influencia o Desenvolvimento das Funções Psicológicas Superiores?
}

\author{
Silvia Nara Siqueira Pinheiro \\ Universidade Federal de Pelotas - Pelotas - RS - Brasil \\ Magda Floriana Damiani \\ Universidade Federal de Pelotas - Pelotas - RS - Brasil \\ Bento Selau da Silva Junior \\ Universidade Federal do Pampa - Jaguarão - RS - Brasil
}

\section{Resumo}

O trabalho relata uma intervenção que teve como objetivo investigar se o jogo com regras explícitas influencia o desenvolvimento das funções psicológicas superiores (FPS) e o rendimento escolar de alunos com história de fracasso escolar no ensino fundamental. A intervenção ancorouse na psicologia histórico-cultural. Os alunos participantes foram dois meninos e uma menina do $3^{\circ}$ e o $4^{\circ}$ ano com idade entre 9 e 11 anos. $\mathrm{A}$ intervenção ocorreu por meio dos jogos de memória, cara a cara e damas. Os instrumentos utilizados para avaliar os efeitos da intervenção foram entrevistas semi-estruturadas com a família, professores e alunos, boletim escolar, observação e avaliação assistida dos testes WISC III e TDE junto aos alunos. As análises dos dados orientaram-se pelas modalidades microgenética e temática. Os resultados indicam que a aprendizagem, ocorrida nas intervenções, promoveu o desenvolvimento das FPS refletindo no desempenho escolar dos alunos.

Palavras-chave: Jogos; fracasso escolar; psicologia histórico-cultural.

\section{Does the game with explicit rules Influence the Development of Higher}

\section{Psychological Functions?}

\begin{abstract}
The paper describes an intervention that aimed to investigate whether the game with explicit rules influences the development of higher psychological functions (FPS) and the academic performance of students with school failure history in elementary school. The intervention anchored in the historical-cultural psychology. The students were two boys and a girl from the 3 rd and 4 th year aged 9 and 11 years. The intervention was through memory games, face to face and checkers. The tools used to evaluate the effects of the intervention were semi-structured interviews with family, teachers and students, school report, observation and evaluation of assisted WISC III and TDE tests to the students. Data analyzes were guided by microgenetic and thematic terms. The results indicate that the learning that took place in the interventions, promoted the development of FPS reflecting the academic performance of students.
\end{abstract}

Keywords: games; school failure; historical-cultural psychology.

\section{¿El Juego con Reglas Explícitas Influencia el Desarrollo de las Funciones}

\section{Psicológicas Superiores?}

\section{Resumen}

El estudio relata una intervención que tuvo como objetivo investigar si el juego con reglas explícitas influencia el desarrollo de las funciones psicológicas superiores (FPS) y el rendimiento escolar de alumnos con historia de fracaso escolar en la enseñanza fundamental. La intervención se ancló en la psicología histórico-cultural. Los alumnos fueron dos niños y una niña del $3^{\text {er }}$ y el $4^{\circ}$ curso con edad entre 9 y 11 años. La intervención fue por intermedio de los juegos de memoria, cara a cara y damas. Los instrumentos utilizados para evaluar los efectos de la intervención fueron entrevistas semiestructuradas con la familia, profesores y alumnos, libreta de calificaciones, observación y evaluación asistida de los testes WISC III y TDE junto a los alumnos. El análisis de los datos se basó en las modalidades microgenética y temática. Los resultados indican que el aprendizaje, ocurrido en las intervenciones, promovió el desarrollo de las FPS reflejando en el desempeño escolar de los alumnos. Palabras clave: juegos; fracaso escolar; psicología histórico-cultural 


\section{Introdução}

O trabalho apresenta os resultados de uma pesquisa de doutorado que teve como objetivo investigar se o jogo com regras explícitas influencia o desenvolvimento das Funções Psicológicas Superiores (FSP - memória, atenção, percepção, raciocínio e tomada de consciência) de alunos com história de fracasso escolar no ensino fundamental. Ancorou-se na perspectiva histórico-cultural, nas ideias de Lev Semenovich Vygotsky, Alexis N. Leontiev e Daniil B. Elkonin e adotou a seguinte definição de fracasso escolar: apresentar pelo menos um episódio de repetência.

O fracasso escolar tem presença marcante na realidade brasileira atual, como demonstram os dados obtidos pelo Instituto Brasileiro de Opinião Pública e Estatística (IBOPE) em pesquisa realizada no primeiro semestre de 2011. Esse Instituto realizou uma avaliação do desempenho escolar de 6 mil alunos do $3^{\circ}$ ano do ensino fundamental de escolas municipais, estaduais e privadas de todas as capitais do país (IBOPE, 2011). Os resultados da pesquisa informam que mais de $40 \%$ dos alunos concluíram o $3^{\circ}$ ano do ensino fundamental sem o nível de aprendizado esperado em leitura, na matemática $50 \%$ dos alunos não apresentaram o desempenho considerado necessário e na avaliação da escrita a média nacional ficou em 68,1 pontos. Dos dados expostos, infere-se que existe um percentual bastante significativo de alunos que não atingiram as competências esperadas para o $3^{\circ}$ ano na leitura (175 pontos), na escrita (75) e na matemática (175 pontos), nos testes realizados. Esses dados indicam que o fracasso escolar, ainda que muito estudado, continua a merecer a atenção dos pesquisadores para que possa ser combatido.

Patto (1990) considera que o fracasso escolar é um fato social concreto multideterminado e deve ser olhado pelo ângulo das relações sociais e não somente pelo ângulo do aluno e da família. Seguindo esse pressuposto, encontramos os princípios da psicologia histórico-cultural que, mais recentemente, têm sido utilizados como importantes subsídios para entender o fracasso escolar, focando na história e nas características da cultura da sociedade na qual ele ocorre.

A ideia central dessa perspectiva teórica é de que na interação social e por intermédio do uso de instrumentos materiais e psicológicos (signos) - principalmente a linguagem - ocorre o desenvolvimento (Vygotsky, 1995, 2009; Luria, 1988). A linguagem é essencial para o processo de transmissão do conhecimento de uma geração para outra e possibilita o aparecimento das FPS. Para Vygotsky (1995), a gênese do comportamento humano ocorre por meio do desenvolvimento das FPS, na interação social e mediada pelo uso de signos.

Vygotsky (1995) defendia a ideia de que todas as funções psicológicas se estruturam no coletivo (interpsíquicas), nas relações com os outros, no âmbito social, passando, posteriormente, a serem funções psíquicas da personalidade (intrapsíquicas). Investigando percepção, memória, atenção e outras FPS, Vygotsky (1995) concluiu que a me- diação pelos signos modifica a estrutura dessas funções, tornando-as conscientes. Elas se desenvolvem por meio da aprendizagem e atuam de forma entrelaçada, formando um vínculo indissociável entre si.

Para entender a relação entre aprendizagem e desenvolvimento, Vygotsky (2009) criou o conceito de zona de desenvolvimento proximal (ZDP) ou imediato. Segundo o autor, nessa zona encontram-se FPS em estado de "brotos", que não estão, portanto, totalmente desenvolvidos e que necessitam da intervenção de outra pessoa, que as dominem. Tal desenvolvimento é o que permitirá à criança, posteriormente, resolver problemas de maneira autônoma. Em outras palavras, o que a criança faz em colaboração hoje, amanhã poderá fazer sozinha. Para Vygotsky (1995, 2009), a aprendizagem efetiva é aquela que se adianta e norteia o desenvolvimento iniciando pelo que está no nível de desenvolvimento real (NDR) e desencadeando o desenvolvimento das funções psicológicas que estão na ZDP.

Para que ocorra o desenvolvimento dessas funções, faz-se necessária a imitação (que o autor diferenciava de mera cópia, já que exige determinado grau de evolução e criatividade por parte de quem imita). Se a imitação se fizer presente, gera-se a possibilidade de aprendizagem. Para Vygotsky (1995, 2009), a imitação é uma das vias principais do desenvolvimento das FPS, mas ele ressalva que só podemos imitar o que está em nossa ZDP; o que ali está, em um determinado momento, em outro poderá estar no NDR, se houver auxílio de alguém mais competente. A ajuda do adulto ou de alguém mais adiantado, que atua na ZDP da criança, pode ser efetivada por meio de perguntas, exemplos, demonstrações.

Essa relação entre aprendizagem e desenvolvimento, segundo Vygotsky (2008), é semelhante àquela que ocorre entre desenvolvimento e jogo,ou seja, este pode ser fonte do desenvolvimento cognitivo e emocional e cria ZDPs nas crianças. O autor (Vygotsky, 2002, 2008) não realizou distinção entre jogo e brincadeira, utilizando esses termos como sinônimos - no sentido de brincadeira ou jogo-de-faz-de-conta e de jogo de regras explícitas. No presente trabalho, utilizar-se-á a palavra jogo, definindo-a, em termos gerais, como uma atividade composta de diferentes ações na qual o motivo, relativo às crianças na idade pré-escolar,está no próprio processo de realização de tal atividade enquanto que, na idade escolar, o motivo está no produto (Vygotsky, 2008; Leontiev, 1988; Elkonin, 2009).

As ideias de Vygotsky (2008), somadas às pesquisas desenvolvidas por Elkonin (2009) e Leontiev (1988), na perspectiva histórico-cultural, originaram uma teoria geral sobre o jogo, abarcando suas características, seu desenvolvimento e sua importância para a evolução intelectual da criança. Focando o jogo na idade escolar, poder-se-ia dizer que, nesta idade, predominam os jogos competitivos e atléticos, envolvendo relações e subordinação do comportamento a certas regras. A criança aprende a seguir regras abdicando de seus impulsos imediatos, postergando o prazer e atingindo autocontrole. O jogo com regras explícitas também possui importância no desenvolvimento da personalidade da 
criança, quando possibilita a auto-avaliação e as noções de moral (Vygotsky, 2008).

$\mathrm{Na}$ revisão de pesquisas sobre o jogo, verificou-se que ele possui diversos enfoques nas diferentes áreas e, nelas, por diferentes teóricos. Grande parte das pesquisas desenvolvidas na perspectiva histórico-cultural foca o jogo na educação infantil (Baldan \& Arce, 2007; Rolim, Guerra, \& Tassigny, 2008; Nascimento; Araújo \& Miguéis, 2009; Nascimento \& Araújo, 2010; Souza, 2010; Baldan \& Hai, 2011). Possivelmente, esse foco seja em consequência de dois motivos: primeiro, as próprias pesquisas de Vygotsky (1995), Leontiev (1988) e Elkonin (2009) que se voltavam para essa faixa etária; segundo, o fato de que nesse período de desenvolvimento a atividade principal da criança é a brincadeira.

No ensino fundamental, e estendendo o foco investigativo aos professores, foram encontradas duas pesquisas: a de Tessaro e Jordão (2007) e a de Pimentel (2008). Essas autoras concluem que o jogo é importante para o aprendizado, mas que os professores não estão preparados para sua adequada utilização. Na busca de pesquisas sobre o jogo de regras explícitas, a partir da abordagem histórico-cultural e no ensino fundamental encontraram-se dois trabalhos: a dissertação de mestrado e a tese de doutorado de Fittipaldi $(2007,2009)$, tendo como amostra alunos com e sem fracasso escolar. Essa pesquisadora trabalhou com as ideias de Vygotsky (1995) e Elkonin (2009) e adotou o "jogo das boas perguntas" e a mesma metodologia de estudo de casos em suas pesquisas. As conclusões obtidas pela pesquisadora nas duas investigações foram de queo jogo de regras explícitas, com apoio da sua mediação e dos alunos mais desenvolvidos promove um tipo de desenvolvimento que expande as possibilidades de aprendizagem da criança, permite identificar suas dificuldades e o tipo de ajuda necessária para nelas criar ZDPs. Essa modalidade de jogo também melhora a autoestima dos alunos e Ihes possibilita interação mais rica e proveitosa com o professor e com seus colegas, além de promover a internalização de novos conteúdos.

A seguir, apresentar-se-á o método da pesquisa realizada em que o jogo de regras explícitas foi utilizado com vistas a desenvolver as FPS das crianças participantes, que apresentavam quadro de fracasso escolar.

\section{Método}

A pesquisa que embasa este artigo caracterizou-se como uma intervenção estruturada em três etapas: avaliação inicial, intervenção com jogos de regras explícitas e avaliação após a intervenção (Damiani, Rochefort, Castro, Dariz, \& Pinheiro, 2013). Foi realizada com três alunos que estavam cursando o $3^{\circ}$ e o $4^{\circ}$ anos do ensino fundamental de escola pública do interior do Estado do Rio Grande do Sul e que apresentavam história de fracasso escolar, ou seja, foram reprovados uma ou mais vezes. Dois alunos selecionados são do sexo masculino (Alcindo e Vinícius), ambos com 11 anos de idade e uma do sexo feminino (Janaína) com 9 anos. Os três alunos são pertencentes à classe social de baixa renda. Os sujeitos foram selecionados, em conjunto com as professoras, por meio da análise dos seus históricos escolares. Cabe a ressalva que os nomes dos sujeitos foram alterados com a finalidade de preservar suas identidades.

A intervenção ocorreu em 2011 e 2012 e teve a duração de 14 encontros individuais com cada sujeito. Ocorria semanalmente, durante o horário escolar com tempo de duração ao redor de 40 minutos, na sala da orientadora educacional. Neles foram utilizados os jogos de "memória" (quatro encontros), "cara a cara" (cinco encontros) e "damas" (cinco encontros). A sequência dos jogos foi estabelecida tomando como critério sua complexidade (começando do mais simples).

Em todos os encontros, realizou-se a mediação entre os sujeitos e o jogo, atuando na ZDP dos primeiros. A mediação consistiu: em repetir as falas das crianças, traduzir e questionar suas jogadas, procurando fazer com que elas tomassem consciência sobre o seu modo de jogar e, consequentemente, pudessem autorregular seu comportamento; fornecer modelos de raciocínio; incentivar os sujeitos a imitar as jogadas da pesquisadora; ajudar, apoiar na realização de jogadas, dando dicas, corrigindo, solicitando explicações sobre elas, refletindo com a criança sobre suas estratégias, mostrando outras possibilidades de jogadas; e elogiar as boas jogadas realizadas - ações inspiradas nos procedimentos utilizados por Vygotsky (2009).

Os encontros foram gravados e desgravados, e as observações da pesquisadora foram anotadas em diário de campo (Yin, 2010). Conversas informais com a orientadora educacional da escola, bem como com as professoras também forneceram informações, igualmente anotadas nesse diário.

Os instrumentos utilizados para coletar os dados sobre as FPS dos sujeitos e seu desempenho escolar, na avaliação inicial e final dos alunos (nove encontros) foram o boletim de desempenho escolar, o Teste de Desempenho Escolar (TDE) (Stein, 1994) e os subtestes de informação, compreensão, dígitos, semelhanças e o de completar figuras da Escala de Inteligência Wechsler para Crianças - WISC - III (Figueiredo, 2002). Para as mães (seis encontros) e professoras (sete encontros) foram utilizadas, na avaliação inicial e final, entrevistas semi-estruturadas (Yin, 2010).

A aplicação dos testes WISC III e TDE foi realizada de modo assistido (Linhares, Maria, Escolano, \& Gera, 1998) teve como suporte as ideias de Vygotsky, sobre avaliação voltada à ZDP e não ao NDR e, as de Feuerstein (Linhares, Escolano, \& Enumo, 2006). Ela fornece indicadores do potencial de aprendizagem da criança, avaliando-a em dois momentos: desempenho sozinha e com assistência. A avaliação assistida possibilita informações prospectivas e não retrospectivas do aluno e pode, segundo Linhares e cols. (2006), ser utilizada em testes psicométricos tradicionais como, por exemplo, o WISC III.Outro fato é que a correção de ambos os testes restringiu-se a acertos e erros. Esses testes foram selecionados em função de que sua aplicação, antes e após as intervenções, possibilitaria avaliar avanços 
em termos das funções psicológicas (memória, atenção, percepção e raciocínio) (Figueiredo, 2002), trabalhadas por meio dos jogos, bem como das habilidades de escrita, de aritmética e da leitura que são importantes para o desempenho escolar.

Os métodos de análise utilizados neste estudo tiveram o caráter qualitativo: foram o microgenético (Góes, 2000) e a análise de conteúdo do tipo temática (Minayo, 1993). As duas temáticas abordadas foram: a) o desenvolvimento das principais FPS trabalhadas na intervenção - memória, atenção, percepção, raciocínio - e avaliadas por meio dos subtestes do WISC III e das observações realizadas durante os encontros; e b) o desempenho escolar acompanhado por meio do boletim de notas, do teste TDE e entrevistas semi-estruturadas. Todos os dados analisados foram submetidos aos processos de triangulação (Duarte, 2009; Yin, 2010) entre si. A seguir, serão expostos alguns achados e a discussão.

\section{Achados e discussão}

Antes de proceder à descrição e à discussão dos achados obtidos nas intervenções por meio de jogos de regras explícitas realizadas junto aos alunos, cabe a ressalva que basicamente, a mesma intervenção foi realizada com os três sujeitos, embora houvesse diferenças de percurso no processo interventivo realizado com cada um, devido as suas individualidades. Devido a limitações provocadas pela amplitude das possibilidades de análise tomou-se a decisão de apresentar os achados dos três alunos em conjunto e estruturados da seguinte maneira: intervenção, efeitos da intervenção sobre o desenvolvimento das FPS e sobre o desempenho escolar. Na descrição dos achados, optou-se por transcrever as falas das crianças, mães e professoras sem correção.

\section{Intervenção}

Neste tópico explicar-se-á como se realizou a intervenção por meio dos jogos de "memória", "cara a cara" e "damas". O jogo mediado pela pesquisadora e pela linguagem se constituiu no estímulo externo, usado para desenvolver as FPS que poderiam, em consequência, auxiliar nas aprendizagens escolares dos alunos. As FPS percepção, atenção, memória, raciocínio e tomada de consciência das ações, foco principal da intervenção,foram trabalhadas conjuntamente em cada encontro e em todos os jogos utilizados.

No primeiro encontro em que foi proposto o uso de cada jogo, as regras desse jogo eram explicadas. Jogava-se a primeira partida sem possibilitar o apoio, para identificar o NDR do sujeito em relação a tal jogo, ou seja, o que eles sabiam fazer de maneira autônoma. Nas partidas seguintes, conforme a necessidade de cada um, era fornecido apoio para que fossem aprendendo a jogar com mais adequação. Em todos os jogos as regras foram sempre retomadas quando se fazia necessário.
As primeiras partidas jogadas com os três sujeitos logo mostraram que eles não conseguiam seguir as regras dos jogos. Por exemplo: formulavam perguntas inadequadas no jogo "cara a cara" ("É homem? Qual o nome?"), que somente permite perguntas que devem ser respondidas com "sim" ou "não". Assim, suas perguntas não serviam para eliminar personagens e diminuir o número de opções para chegar à figura-alvo a ser descoberta, definida no início do jogo.Ao jogar "cara a cara", não sabiam qual figura deveriam baixar, realizavam descartes inadequados demonstrando possíveis dificuldades para realizar o raciocínio por exclusão, chegando ao final sem a carta que deveria ser identificada no tabuleiro. Não identificavam características comuns das figuras e, em decorrência, não as agrupavam e não formulavam boas perguntas, ou seja, perguntas que eliminassem várias figuras no jogo.

No jogo de "damas", andavam no tabuleiro com suas peças "para trás", sentido que não é permitido. No jogo de "memória", não organizavam as peças em cima da mesa para que pudessem, depois, serem mais facilmente localizadas. Também não fixavam o lugar das figuras sobre a mesa e demoravam a encontrar os pares, repetindo as jogadas em que não tinham obtido êxito anteriormente.

Essas maneiras de jogar podem indicar dificuldades de atenção, memorização e compreensão, entre outras FPS envolvidas no jogar, pois, como já referido anteriormente, as FPS funcionam de maneira entrelaçada e indissociável (Vygotsky, 1995). A forma como jogavam, parecia ser, igualmente, indicativa de dificuldades para desenvolver estratégias, realizar raciocínios.

O apoio nos jogos, foco da intervenção, foi baseado na constatação de Vygotsky (1995), que ao investigar a gênese das FPS percebeu que as crianças em idade escolar cometiam menor número de erros no cumprimento de uma tarefa, se essa atividade fosse mediada por adulto, utilizando-se de estímulos auxiliares externos, especialmente a linguagem. Para ele, realizar a mediação é trabalhar na ZDP; implica atividade colaborativa, apoio às crianças na realização de tarefas que ainda não conseguiam realizar sozinhas. Nos processos de mediação levados a cabo na intervenção, a intenção era desenvolver nos sujeitos estratégias que lhes permitissem ter êxito nos jogos, apresentando-lhes modelos referenciais de análise, reflexão, planejamento, raciocínio, estratégias para controlar a atenção, a memória, a serem imitados. O objetivo era, igualmente, levá-los a tomar consciência da necessidade e da forma de produzir tais ações, como mostra o relato que segue.

Ao jogar "memória", por exemplo, era chamada a atenção dos sujeitos para a organização das peças, suas características e localização das figuras sobre a mesa. Na memorização do lugar das peças, por exemplo, a pesquisadora falava: "Esse é o bombeiro, estava por aí!". Também eram assinaladas as jogadas repetitivas e pouco produtivas - como desvirar uma figura conhecida em primeiro lugar, várias vezes - trabalhando na ZDP dos alunos, ou seja, no desenvolvimento das FPS necessárias à realização das tarefas propostas, isto é, encontrar os pares com mais facilidade. 
Outra forma de mediação adotada foi sentar ao lado dos alunos, no jogo "cara a cara", chamando a atenção para os detalhes das figuras que estavam no tabuleiro e formulando as perguntas em conjunto com eles. Auxiliá-los nos descartes foi outro apoio possibilitado: por exemplo, em uma das partidas, a pesquisadora perguntou para Janaína se havia no tabuleiro mais alguma figura com chapéu, ajudando-a a utilizar melhor sua percepção e atenção, melhorando suas jogadas.

Ao retomar as regras do jogo, no "cara a cara", por exemplo, a pesquisadora chamava a atenção para o fato de que não poderiam realizar três perguntas ao mesmo tempo, pois isso impossibilitaria uma resposta afirmativa ou negativa. Relembrava, também, a impossibilidade de a primeira pergunta do jogo ser sobre o sexo da figura.

No jogo de "damas", a pesquisadora solicitava aos alunos que analisassem o tabuleiro e percebessem as possibilidades de jogadas. Para que aprendessem a fazer isso, ela realizava o planejamento de suas próprias jogadas em voz alta, para que as crianças percebessem suas estratégias e raciocínios. Também analisava as jogadas das crianças e, caso fosse necessário, permitia que refizessem suas jogadas.

No decorrer dos encontros, em que os jogos foram realizados com apoio, perceberam-se mudanças na maneira de jogar dos alunos, pois suas jogadas cresceram em qualidade: ao longo do tempo, passaram a encontrar pares com mais facilidade no jogo de "memória", possivelmente porque prestavam mais atenção aos detalhes das figuras e aos lugares onde elas estavam. No jogo "cara a cara", as perguntas dos sujeitos tornaram-se melhor formuladas possibilitando maior número de descartes, o número de perguntas para identificação da figura-alvo diminuiu, os descartes foram adequados, indicando que as crianças estavam realizando o raciocínio por exclusão.

\section{Efeitos da intervenção sobre o desenvolvimento das FPS}

Analisando o jogo de regras, poder-se-ia afirmar que ele possibilita interações sociais que se vão modificando conforme a criança vai aprendendo e se desenvolvendo. A intervenção, por meio do jogo, permitiu à pesquisadora observar quais habilidades e conhecimentos atingiam o NDR e que outras ZDPs estavam sendo desenvolvidas. Para Vygotsky (2009), o que está em determinado momento na ZDP, em outro momento poderá estar no NDR, se houver aprendizagem mediada. Trabalhar na ZDP não é criar, no jogo, um nível de exigência que a criança não possa atingir no momento - mesmo que Ihe seja possibilitado o apoio ou trabalhar com um jogo no qual ela não tenha nenhuma dificuldade, mas sim saber criar a dificuldade adequada para que ela, com apoio, possa resolvê-la. É saber retirar o apoio e novamente possibilitá-lo em outras jogadas, para ir promovendo a aprendizagem e o desenvolvimento da criança.
À medida que os encontros se desenvolviam, percebia-se que os alunos tomavam consciência de suas dificuldades. Janaína, por exemplo, explicou que não ganhou uma das partidas do jogo "cara a cara" porque não prestou atenção. Alcindo, no jogo de "memória", depois de ter realizado várias jogadas erradas falou: "Não é este! Errei! Tô repetindo a mesma jogada!". Indícios como estes, que se constituem em exemplos do que ocorreu nos encontros, permitem levantar a hipótese de que os jogos de "memória", "cara a cara" e "damas" (estímulos auxiliares externos), juntamente com a mediação da pesquisadora, promoveram, nos sujeitos da intervenção, uma tomada de consciência sobre seus processos mentais. Também possibilitaram a autoavaliação, ilustrando a afirmação de Elkonin (2009), de que por meio do jogo a criança se avalia, conscientemente, quanto as suas habilidades e dificuldades.

Após os alunos tomarem consciência sobre suas jogadas e sobre os problemas que elas apresentavam, percebeu-se que passaram a imitar os comportamentos e as jogadas da pesquisadora. Imitavam estratégias (organização das figuras sobre a mesa, repetição das perguntas feitas pela pesquisadora, movimento das peças no tabuleiro) e criavam outras, desenvolvendo suas ações em voz alta. Ao término de uma partida de "damas", Alcindo disse: "Agora eu já sei o teu truque, sei dos teus truques! Tu vais pelos cantos e eu vou te imitar".

Para Vygotsky (1995), é necessário lembrar, a imitação é uma das vias principais de aprendizagem e de desenvolvimento das FPS. Se ela ocorre, significa que existe certo entendimento, compreensão da situação pelo sujeito e tomada de consciência da ação do outro. Ocorrendo a tomada de consciência, o homem analisa, planeja e decide a melhor ação a realizar no momento (Ratner, 1995), fato este constatado, por exemplo, na fala de Janaína, durante uma partida de "damas": "Agora, se eu vim pra cá, a senhora vai, si eu venho pra cá." (sic).

Além dos extratos e das observações da intervenção, o desenvolvimento das FPS foi avaliado antes de iniciar a intervenção e ao final dessa por meio das questões dos subtestes da área verbal de informação, aritmética, dígitos, semelhanças e da área de execução o subteste de completar figuras do WISC III, como anteriormente relatado. Salienta-se que avaliação final limitou-se à reaplicação dos itens nos quais a pesquisadora tinha possibilitado apoio e dos que os sujeitos não haviam acertado na avaliação inicial.

Analisando os resultados da avaliação Inicial de Alcindo constatou-se que, em compreensão, semelhança, informação e completar figuras, o menino obteve um bom número de acertos, ultrapassando a metade das questões propostas. Os resultados obtidos após a intervenção sugerem que não houve avanços no número de acertos nas questões dos subtestes de informação, semelhanças e compreensão. Os subtestes de compreensão e semelhanças indicam altos níveis de conhecimento prático e fluência verbal. No subteste de informação, o resultado da avaliação inicial também já era bom e acredita-se que não sofreu alterações, provavelmente em decorrência de que as questões avaliam, 
essencialmente, o conhecimento adquirido, ou seja, conceitos científicos já internalizados. Os conteúdos incluídos neste subteste não foram trabalhados na intervenção e, possivelmente, também não o foram na classe regular, pois não fazem parte do currículo designado para o $4^{\circ}$ ano do ensino fundamental. Assim, não haveria razão para a alteração no escore do menino, na avaliação final.

Percebeu-se maior dificuldade, por parte de Alcindo, nas questões do subteste de dígitos, principalmente, no de ordem inversa, sugerindo problemas de atenção, de memória imediata, de capacidade de reversibilidade, de concentração, de conhecimentos aritméticos e de raciocínio lógico. $\mathrm{Na}$ avaliação final, entretanto, ocorreram avanços nas questões dos subtestes de dígitos de ordem direta e inversa. Também houve progressos no subteste de completar figuras, sugerindo desenvolvimento das FPS neles envolvidas -como atenção, memória, raciocínio e reversibilidade do pensamento. Esse desenvolvimento foi confirmado quando houve a triangulação dos resultados dessas questões com os obtidos nas questões do TDE - área de aritmética (divisão e multiplicação) - e com as notas escolares.

Janaína e Vinícius obtiveram na avaliação inicial resultados muito semelhantes entre si: ambos, de uma maneira geral, acertaram aproximadamente metade das questões propostas para cada subteste, indicando dificuldades em todas as áreas investigadas (memória, atenção, percepção e raciocínio). No subteste de completar figuras, o resultado foi um pouco melhor, ultrapassando a metade das questões. No subteste de aritmética, o fato de ter dificuldade na leitura, provavelmente, prejudicou seu desempenho. Janaína apresentou nos subtestes de compreensão e dígitos (ordem direta e inversa) dificuldades maiores ainda do que as de Vinícius, pois a aluna não compreendia o que deveria realizar no teste.

Os resultados das questões do WISC III, de Janaína e de Vinícius, após a intervenção sugeriram que houve avanços no número de acertos em todos os subtestes. Percebeu-se um avanço maior nos subtestes de semelhanças e de completar figuras indicando que houve desenvolvimento das FPS percepção, atenção, memória, raciocínio, organização e linguagem, nelas envolvidas.

O desenvolvimento dos alunos foi confirmado quando se triangularam os resultados desses subtestes com os obtidos no TDE - leitura, escrita e aritmética - as falas das mães, professoras, e com as notas escolares, decorrendo a aprovação deles no final do ano.

\section{Efeitos da intervenção sobre o desempenho escolar}

Para discutir esses efeitos, serão apresentados dados relativos às modificações observadas no desempenho escolar dos sujeitos das intervenções. Esses dados foram obtidos por meio das entrevistas realizadas após as intervenções junto às mães, às professoras, os próprios sujeitos e conversas informais com a OE. Também serão apresentados os resultados das questões do TDE igualmente apli- cadas antes e depois da intervenção, pois este teste tem relação direta com o desempenho em tarefas escolares. Com a finalidade de facilitar a percepção dos efeitos das intervenções, antes de apresentar tais efeitos, um breve relato da situação dos sujeitos antes da sua realização será incluído.

Alcindo foi reprovado no $4^{\circ}$ ano; matemática era a área em que apresentava mais dificuldades e pior desempenho. Frequentava a classe de reforço desde o $1^{\circ}$ ano. Tinha falta de atenção, ansiedade, o que segundo a professora, comprometia a memorização dos conteúdos. Obtinha bons resultados em português, ciências e estudos sociais. No TDE observou-se pelo número pequeno de erros cometidos pelo aluno, que Alcindo apresentava boa escrita, excelente leitura e que suas dificuldades concentravam-se na aritmética. Nessa área, o aluno não dominava o mecanismo das operações de divisão, multiplicação e subtração, não sabia a tabuada, demonstrava falta de atenção (olhava para os lados, conversava sobre outros assuntos), dizia "estou cansado" e "não sei, não sei", durante a realização das questões. Nos resultados obtidos após a intervenção constatou-se que ocorreram avanços na escrita e melhoras significativas na aritmética (divisão, multiplicação e subtração). Ao final da intervenção tanto mãe como professora indicaram que o aluno havia demonstrado melhor rendimento e atenção em todas as disciplinas o que possibilitou sua aprovação para a série seguinte. Alcindo declarou que gostou do trabalho e percebeu mudanças na aprendizagem ("Eu não sabia quase nada. Quando a senhora chegou aqui, eu comecei a saber.") Janaína estava repetindo $03^{\circ}$ ano, apresentava dificuldades em todas as disciplinas. Sua leitura era lenta, escrevia faltando letras, o que, por vezes, tornava ilegíveis as palavras. Na matemática apresentava melhor rendimento, mas sempre realizava cálculos com auxílio do desenho de pauzinhos. Apresentava dificuldades para memorizar o conteúdo, tudo a distraía, esquecia o que estava fazendo. Somente apresentava bom desempenho em educação artística.

Os resultados do TDE, antes de iniciar a intervenção, confirmaram que Janaína apresentava dificuldades na escrita, na leitura e melhor desempenho na aritmética. Concluiu-se que a aluna estava ainda em processo de alfabetização. $\mathrm{Na}$ avaliação final, depois da intervenção, os resultados obtidos nas questões do TDE indicaram avanços em todas as áreas.

No decorrer da intervenção foi relatado pela orientadora educacional que Janaína tinha mudado, estava mais ligada, mais concentrada. As entrevistas realizadas pós-intervenção sugerem que ocorreram mudanças na aprendizagem de Janaína. Segundo a mãe, sua filha hoje "escreve melhor e já lê melhor". Antes, sua leitura "era muito demorada, lia pouco e agora lê mais, correndo, bem". Ela "não sabia o que estava escrevendo, ela inventava e escrevia, fazia que lia mas não lia". Sentia que a filha estava mais atenta, que era muito desligada. Relatou que "a professora escreve e ela copia direito, escreve certo". Antes, "ela não sabia ler. Como ela ia passar de série? Agora vai passar lendo". Segundo a professora, em entrevista após a intervenção, a aluna era aérea e apresentava falta de concentração. Quanto à leitura: "lia pouco quando iniciou o 
trabalho e hoje lê melhor, mas não o esperado para o $3^{\circ}$ ano. Mas ninguém tá; a turma é fraca. Tem que melhorar". Na matemática, em ciências e estudos sociais o rendimento melhorou. Janaína avaliou os encontros como "bom, eu aprendi antes não lia tanto e agora eu leio mais".

Vinícius repetiu duas vezes o $2^{\circ}$ ano e uma vez o $3^{\circ}$. Teve atendimento por parte da professora da educação especial, por um tempo. Depois, não houve mais possibilidade, pois havia outras crianças para serem atendidas. A mãe disse que ele apresenta dificuldade em ciências, português e na leitura, por "não saber ler, ele só copia", "tem preguiça", "faz tudo rapidamente e quer conversar", "é ansioso e desorganizado". Ela não conseguia compreender como ele estava com média em algumas disciplinas, se não sabia ler. $\mathrm{Na}$ matemática, a mãe achava que como só envolve cálculos, o menino conseguia realizá-los com mais facilidade. A professora informou que sua leitura é silabada e lenta. Assim descreveu o comportamento do menino nesta área: "ele conhece algumas palavras e letras e chuta por serem parecidas, quando lê". Relatou que sua escrita tem palavras legíveis e ilegíveis. Na matemática, considerava-o "ótimo" dizendo que resolvia problemas, realizava cálculos, sempre por escrito e, às vezes, mentalmente ("alguns exercícios ele nem monta e dá a resposta"). Assim nessa disciplina como também na educação artística, o aluno apresenta bom desempenho. No geral, era visto como desatento, agitado ("não fica parado"), tímido, não demonstrando interesse nas atividades escolares ("só quer desenhar"), exceto nas aulas de educação física.

Os resultados do TDE antes da intervenção demonstraram que o aluno apresentava muitas dificuldades na escrita, cometendo vários erros na mesma palavra tornado-a ininteligível. Na leitura, cometia vários erros em uma mesma palavra e procurava adivinhar a palavra lendo apenas o seu início. Sua leitura, por vezes, era ininteligível. Lia em voz baixa - sendo solicitado, por diversas vezes, que falasse mais alto -; rápido, olhava para os lados, mexia-se na cadeira, contorcia o corpo e, várias vezes, dizia que não sabia ler. Apresentava melhor desempenho em aritmética, realizava cálculos mentais com rapidez e, em algumas situações, com o apoio de bolinhas desenhadas em uma folha de papel.

As entrevistas realizadas ao final da intervenção com a mãe e a professora, sugerem que ocorreram mudanças na aprendizagem de Vinícius. A mãe expôs que seu filho meIhorou muito, principalmente no português: "é, ele modificou, melhorou um monte, principalmente na leitura, português. Não escrevia direito e não sabia ler. Minha mãe está admirada". Continuando, disse que as notas foram boas, "ele está prestando atenção em aula" e há expectativa de que ele "passe no final do ano".

A professora, durante o tempo em que foi realizada a intervenção, relatou que o aluno, a partir dos encontros, estava demonstrando melhor comportamento, rendimento, motivação, interesse, vontade, atenção e memória. Ao final da intervenção, ela referiu que ele: "teve progresso, com certeza. Tinha mudado o comportamento na sala de aula ele perguntava mais, como se escrevia as palavras se era com ç, ss". Segundo a professora, sua leitura melhorou: "ele lia pelo desenho das palavras, mas não sabia", ele "tinha timidez", "perdeu o medo de perguntar", "não tem vergonha dos colegas", "vai até minha mesa e pergunta como se escreve; em decorrência, sua escrita melhorou". O aluno foi aprovado para a série seguinte. Vinicius avaliou os encontros dizendo "aprendi bastante coisa, a ler melhor, pensar melhor."

Os três sujeitos melhoraram seus desempenhos na escrita, na aritmética e na leitura. Percebeu-se que Janaína e Vinícius tinham se alfabetizado e que em Alcindo ocorreram modificações significativas na aritmética (divisão, multiplicação e subtração).

Como descrito anteriormente, os efeitos da intervenção foram avaliados por meio de diferentes instrumentos e os dados coletados foram submetidos a um amplo processo de triangulação, que indicou significativa convergência desses dados entre si. Tal fato sugere que os avanços obtidos foram decorrentes da intervenção por meio dos jogos de regras explícitas, embora não se possa descartar a possibilidade de que outros fatores tenham também influenciado tais avanços.

Os achados da intervenção vieram ao encontro dos obtidos por Fittipaldi $(2007,2009)$ e por Pimentel (2008) que indicam que o jogo mediado instiga a criança avançar em seu desempenho intelectual, desenvolver suas habilidades, efetuar diferentes raciocínios, ou seja, promove o desenvolvimento de suas FPS e a criação de ZDPs. Pimentel (2008) ressalta que o jogo de regras apresenta o mesmo potencial de promover modificações no psiquismo do que o jogo protagonizado, típico da pré-escola.

\section{Considerações finais}

A presente pesquisa, que investigou se o jogo com regras explícitas influencia o desenvolvimento das FPS de alunos com história de fracasso escolar no ensino fundamental, gerou resultados positivos. Há diversos indícios de que a aprendizagem, ocorrida durante os encontros em que os estudantes jogaram com a pesquisadora, de maneira mediada, promoveu o desenvolvimento das FPS refletindo-se, também, em seu desempenho escolar. Os avanços foram identificados por meio da análise microgenética de episódios ocorridos durante os encontros (observação), triangulada com os dados obtidos nas entrevistas semi-estruturadas junto à mãe, à professora e os próprios sujeitos, juntamente com os resultados dos testes - WISC III e TDE - e as notas escolares. Os achados sugerem que o jogo com regras explícitas, utilizado com a mediação da pesquisadora, criou ZDPs, gerando desenvolvimento cognitivo, ratificando as ideias de Vygotsky (2008) sobre essa atividade. O jogo foi um mediador eficiente entre a aprendizagem e o desenvolvimento dos sujeitos, que tinham histórias de fracasso escolar. Esta conclusão reforça a ideia de que o fracasso não deve ser naturalizado, mas ser compreendido como uma construção histórica e cultural passível de ser modificada. Por isso, precisamos criar caminhos, brechas para a superação 
dessa situação. O jogo com regras explícitas constitui-se em um caminho para desnaturalizar o fracasso e alcançar o sucesso escolar.

Infere-se que os alunos, ao aprenderem a jogar, desenvolveram as FPS - percepção, memória, atenção, raciocínio e tomada de consciência - o que, possivelmente teve repercussão em seu desempenho escolar. Este aprendizado possibilitou a aprovação dos três alunos ao final do ano letivo.A partir dos efeitos da intervenção, acredita-se que o uso de jogos de regras deve ser incentivado no contexto escolar, como importante ferramenta de aprendizagem e desenvolvimento. Para concretizar as intervenções por meio de jogos, seria imprescindível que os professores refletissem sobre o fracasso escolar, se apropriassem dos conceitos da psicologia histórico-cultural, e compreendessem como o trabalho guiado por tais conceitos pode ser frutífero, como ocorreu nesta intervenção.

A escola e o professor têm papel importante no desenvolvimento dos seus alunos, pois transmitem conhecimentos historicamente construídos e apresentam potencial para desenvolver as FPS. Em síntese, ajudam a humanizá-los. Se a escola não cumprir esse importante papel, deverá ter claro que colaborará para o aluno ficar à margem da sociedade. Aprender a ler, a escrever, a realizar cálculos e a jogar desenvolve as FPS e, possivelmente, contribui para o papel social que será ocupado pelo aluno no futuro.

Deve-se acreditar que aprender é possível, embora, às vezes, seja preciso adequar ou rever os conteúdos a serem ministrados e as formas de ensino, procurando novas formas na mediação do conhecimento, para que a aprendizagem possa ser efetivada com sucesso.

Por fim, sugere-se que novos estudos devem ser realizados com alunos dos anos iniciais do ensino fundamental, que apresentem dificuldades no processo de aprendizagem, com o objetivo de validar a intervenção com jogos de regras explícitas e possibilitar a generalização dos resultados.

\section{Referências}

Baldan, M. \& Arce, A. (2007). A Contribuição da Psicologia HistóricoCultural no Desenvolvimento da Pedagogia do Jogo de Elkonin. Em Colóquio Internacional Marx Engels, Anais eletrônicos do Colóquio Internacional Marx Engels. Campinas: CERMAX. Recuperado: 30 ago. 2011. Disponível: http://www.unicamp.br/ cemarx/anais_v_coloquio_arquivos/arquivos/comunicacoes/gt5/ sessao4/Merilin_Baldan.pdf.

Baldan, M. \& Hai, A. A.(2011). Jogo e infância em Elkonin-APsicologia Histórico-Cultural pensando o desenvolvimento infantil. Em $\mathrm{X}$ Congresso Nacional De Psicologia Escolar e Educacional. Anais do X Congresso Nacional de Psicologia Escolar e Educacional. Maringá: ABRAPEE. Recuperado: 28 ago.2014 Disponível: http:// www.abrapee.psc.br/xconpe/trabalhos/1/148.pdf.

Damiani, M. F., Rochefort, R. S., Castro, R. F., Dariz, M. R., \& Pinheiro, S. S. (2013). Discutindo pesquisas do tipo intervenção pedagógica.
Cadernos de Educação-Faculdade de Educação,2(45), 57-67. Recuperado: 06 jun. 2014. Disponível: http://periodicos.ufpel.edu. br/ojs2/index.php/caduc/article/view/3822.

Duarte, T. (2009). A possibilidade da investigação a 3: reflexões sobre a triangulação (metodológica). Centro de Investigação e Estudos em Sociologia (CIES) e-Working Papers, 60, 1-24. Recuperado: 04 out. 2012. Disponível: http://www.cies.iscte.pt/destaques/ documents/CIES-WP60_Duarte_003.pdf.

Elkonin, D. B. (2009). Psicologia do jogo. (2ª ed.) São Paulo: Martins Fontes.

Figueiredo, V. (2002). WISC III: Escala de Inteligência Wechsler para Crianças: Manual/David Wechsler. Adaptação e Padronização de uma amostra Brasileira ( $3^{a}$ ed.). São Paulo: Casa do Psicólogo.

Fittipaldi, C. B.(2007). Jogar para ensinar - Jogar para aprender: o jogo como recurso pedagógico na construção de conceitos escolares e desenvolvimento de habilidades cognitivas, no Ensino Fundamental. Tese de Doutorado, Pontifícia Universidade Católica de São Paulo, São Paulo - SP.

Fittipaldi, C. B. (2009). Jogo e mediação social: um estudo sobre o desenvolvimento e a aprendizagem de alunos do ensino fundamental. Estudos em Avaliação Educacional, 20(42), 125150. Recuperado: 3 jul. 2010. Disponível: http://www.fcc.org.br/ pesquisa/publicacoes/eae/arquivos/1471/1471.pdf.

Góes, M. C. R. (2000). A abordagem microgenética na matriz histórico-cultural: uma perspectiva para o estudo da constituição da subjetividade. Cadernos Cedes, (50), 9-25.

Instituto Brasileiro de Opinião Pública e Estatística [lbope] (2011). Prova ABC traz dados inéditos sobre a alfabetização das crianças no Brasil. Ibope.Recuperado: 05 set. 2011. Disponível: http://www. ibope.com.br.

Leontiev, A. N. (1988). Os Princípios Psicológicos da Brincadeira Escolar. Em L. S. Vigotskii, A. R. Luria, \& A. N. Leontiev. Linguagem, Desenvolvimento e Aprendizagem (3a ed.) (pp. 119142). São Paulo: Ícone: Editora da Universidade de São Paulo.

Linhares, M. B. M., Escolano, A., \& C. M.; Enumo, S. R. F. (Orgs.) (2006). Avaliação Assistida: fundamentos, procedimentos e aplicabilidade. São Paulo: Casa do Psicólogo.

Linhares, M. B. M., Maria, M. R. S., Escolano, A. C. M., \& Gera, A. A. S. (1998). Avaliação Assistida: uma abordagem promissora na avaliação cognitiva de crianças. Temas em Psicologia, 6(3), 231254. Recuperado: 4 mar. 2011. Disponível: http://pepsic.bvsalud. org/pdf/tp/v6n3/v6n3a07.pdf.

Luria, A. R.(1988). Vigotskii. Em Vigotskii, L. S., Luria, A. R., \& Leontiev, A. N..Linguagem, Desenvolvimento e Aprendizagem. $\left(3^{a}\right.$ ed.)(pp. 21-37). São Paulo: Ícone: Editora da Universidade de São Paulo. 
Minayo, M. C. S. (1993). O desafio do conhecimento: pesquisa qualitativa em Saúde ( $8^{\mathrm{a} e d .}$.). São Paulo: Hucitec.

Nascimento, C. P., Araújo, E. S., \& Miguéis, M. R. (2009). O jogo como atividade: contribuições da teoria histórico-cultural. Psicologia Escolar Educacional, 13(2), 293-302.Recuperado: 21 ago. 2011. Disponível: http://www.scielo.br/scielo.php?pid=S1413$85572009000200012 \&$ script=sci_arttext.

Nascimento, C. P. \& Araújo, E. S. (2010). O conteúdo e a estrutura da Atividade de Ensino na Educação Infantil: o papel do jogo. Em M. O. Moura (Org), Grupo de Estudos e Pesquisa sobre a Atividade Pedagógica (GEPAP e Feusp) (pp.111-134). Brasília: Liber Livro Editora Ltda.

Patto, M. H S.(1990). A produção do Fracasso Escolar: histórias de submissão e rebeldia. São Paulo: T. A. Queiroz.

Pimentel, A. (2008). A ludicidade na educação infantil: uma abordagem histórico-cultural. Psicologia da Educação, (26), 109-133. Recuperado: 21 ago. 2011. Disponível: http://pepsic.bvsalud.org/ scielo.php?script=sci_arttext\&pid=s1414-69752008000100007.

Ratner, C. (1995). A Psicologia Sócio-Histórica de Vygotsky Aplicações Contemporâneas. Porto Alegre: Artes Médicas.

Rolim, A. A. M., Guerra, S. F. G., \& Tassigny, M. M. (2008). Uma leitura de Vygotsky sobre o brincar na aprendizagem e no desenvolvimento infantil. Revista Humanidades, 23(2), 176-180, Recuperado: 22 ago. 2011. Disponível: http://www.slideshare.net/ lucima/2633.

Souza, R. A. C. (2010).Um estudo sobre o processo de singularização de crianças através do jogo protagonizado. Dissertação de
Mestrado, Universidade Federal do Ceará, Ceará.

Stein, L. M. (1994). TED: teste de desempenho escolar: manual para aplicação e interpretação. São Paulo: Casa do Psicólogo.

Tessaro, J. P. \& Jordão, A. P. M. (2007) Discutindo a importância dos jogos e atividades em sala de aula. Psicologia.com.pt. Recuperado: 21 out. 2011. Disponível: http://www.psicologia.com. pt/artigos/textos/A0356.pdf.

Vygotski, L. S. (1995). Obras escogidas III - Problemas del desarrollo de la psique.Madrid: Visor.

Vygotsky, L. S. (2002). Jogar e seu papel no desenvolvimento mental da criança. Psychology and Marxism Internet Archive (marxist. org). Recuperado: 14 jun. 2010. Disponível: http://www.marxists. org/archive/vygotsky/works/1933/play.htm.

Vygotsky, L. S. (2008). A brincadeira e o seu papel no desenvolvimento psíquico da criança. (Prestes, Z.,Trad.). Revista Virtual de Gestão de Iniciativas Sociais, 23-36, Jun. Recuperado: 23 mar. 2011. Disponível: http://xa.yimg.com/kq/groups/32960205/729519164/ name/artigo+ZOIA+PRESTES.

Vigotski, L. S. (2009). A construção do pensamento e da linguagem ( $2^{\mathrm{a}}$ ed.). São Paulo: Editora WMF Martins Fontes.

Yin, R. (2010). Estudo de Caso: planejamento e método (4a ed.). Porto Alegre: Bookman.
Recebido em: 24/02/2015

Reformulado em: 16/03/2016

Aprovado em: 20/04/2016

\section{Sobre os autores}

Silvia Nara Siqueira Pinheiro (silvianarapi@gmail.com.br)

Graduada em Psicologia, com Mestrado em Saúde e Comportamento e Doutorado em Educação. Professorado Curso de Psicologia da Universidade Federal de Pelotas.

Magda Floriana Damiani (flodamiani@gmail.com)

Psicóloga, mestre em Psicologia Educacional e doutora em Educação. Docente da Universidade Federal de Pelotas (RS)

Bento Selau da Silva Junior (bentoselau@gmail.com)

Doutor em Educação, coordenador do Programa de Pós-Graduação em Educação da Universidade Federal do Pampa

Trabalho derivado da tese de uma das autoras intitulada: "O jogo com regras explícitas pode ser um instrumento para o sucesso de estudantes com história de fracasso escolar?", realizada na Universidade Federal de Pelotas (UFPel) -Faculdade de Educação no Programa de PósGraduação em Educação 
